\title{
SUDEP and seizure safety communication: assessing if people hear and act
}

Charlotte Young ${ }^{1}$ DCH, MBBS, MRCPsych, Rohit Shankar*1, 2 MBBS, FRCPsych, William Henley ${ }^{2}$ MSc, PhD, Adam Rose ${ }^{1}$ MBBS, MRCPsych, Katie Cheatle ${ }^{1}$ MBBS, Josemir W Sander ${ }^{3,4,5}$ MD, PhD, FRCP

1. Cornwall Partnership NHS Foundation Trust, Threemilestone Industrial Estate Truro TR4 9LD, UK

2. Exeter Medical School, Knowledge Spa, Royal Cornwall Hospital Truro Cornwall TR1 3HD, UK

3. NIHR University College London Hospitals Biomedical Research Centre, UCL Institute of Neurology, Queen Square, London WC1N 3BG, UK

4. Chalfont Centre for Epilepsy, Chalfont St Peter, Buckinghamshire SL9 ORJ, UK

5. Stichting Epilepsie Instellingen Nederland (SEIN), Achterweg 5, 2103 SW Heemstede, Netherlands

\section{*Corresponding author -}

Dr Rohit Shankar

Telephone-+44-1872221553

Fax: - +44-1872 240765

Email: Rohit.shankar@nhs.net

Word count excluding title page, abstract, references and appendix: 1329 words

References: 12

Running title - nocturnal surveillance and seizure safety

Conflict of Interest:

RS is a stakeholder of the 'SUDEP and Seizure Safety Checklist' and the mobile app based on the checklist - EpSMon. RS has received institutional and research support and personal fees from LivaNova, UCB, Eisai, Special Products, Bial and Desitin outside the submitted work. JWS is a member of the SUDEP and Seizure Safety Checklist expert review panel. JWS has received departmental research support from Eisai and UCB Pharma and has been consulted by and received fees for lectures from Bial, Eisai, Janssen and UCB Pharma outside the submitted work.

Acknowledgements 
Eisai UK supported this work in the form of an unconditional institutional project grant. JWS is based at UCLH/UCL Comprehensive Bio-Medical Research Centre, which received a proportion of funding from the Department of Health's NIHR Biomedical Research Centres funding scheme. JWS current position is endowed by the UK Epilepsy Society and he receives research support from the Dr. Marvin Weil Epilepsy Research Fund. WH was funded by the National Institute for Health Research (NIHR) Collaboration for Leadership in Applied Health Research and Care (CLAHRC) for the South West Peninsula. The views expressed in this publication are those of the authors and not necessarily those of the NHS, the NIHR or the Department of Health. 


\begin{abstract}
Background: Sudden unexpected death in epilepsy (SUDEP) is a leading cause of death among people with chronic epilepsy. People with Intellectual Disability (ID) are over represented in this population. The SUDEP and Seizure Safety Checklist ("Checklist") is a tool to discuss risk factors influencing seizures and the risk of SUDEP. It includes questions about the availability of nocturnal monitoring. In Cornwall UK, people with epilepsy and ID and their relatives and carers are routinely advised to consider nocturnal surveillance to reduce harm from potential nocturnal seizures. We assessed the retention of advice provided on nocturnal monitoring and if there were differences between those in residential care and those living with their families.
\end{abstract}

Methods: A postal questionnaire was sent to carers of all people in Cornwall followed by the adult specialist ID epilepsy service. All contacted had received the same advice on SUDEP and nocturnal monitoring at least once in the past year. Each person was categorised into living in a residential setting or with their family group. Inter group differences were compared using Fisher's exact test.

Results: Carers for 170 people were contacted and 121 responded (71\%). The family group had statistically more nocturnal seizures than the residential group. While there was no difference in the awareness of SUDEP the groups differed in their recollection of the person centred discussion of risk with carers in residential setting less aware. Where nocturnal monitoring advice was given it was followed and previously unknown seizures were identified in $75 \%$.

Conclusions: Carers in residential settings are less likely to recall specific person centred discussion of risks to the individual they support as compared to those living with families though general awareness of SUDEP and implementing advice such as nocturnal monitoring is present equally in both groups. In improving detection of nocturnal seizures, audio monitoring may be a useful strategy to reduce risk of harm for people with ID. 


\section{Introduction}

Sudden unexpected death in epilepsy (SUDEP) is the leading cause of death among people with chronic epilepsy and discussing the risk of SUDEP is now strongly recommended as good practice $(2,3)$. A structured and validated tool for risk communication, i.e. the SUDEP and Seizure safety Checklist ("Checklist") $(4,5)$ (appendix 1) could be used to facilitate a person centred discussion on SUDEP and its risk factors.

In the UK, people with epilepsy and Intellectual Disability (ID) tend to live either in family settings or in supported residential arrangements. They may live with their biological families or in "Shared Lives" arrangements (i.e. with other host families). Those who do not live within a family setting may be supported by private sector care providers, funded by the state. Arrangements range from being in their own home with a professional care team, to living in multi-occupancy residential units. Direct care providers are generally not trained clinicians though some larger establishments may have a trained nurse to administer medication. Medical provision for community residential care is provided by the usual local primary care team.

There is an over representation of people with ID amongst people with chronic epilepsy. About half of these people with ID have nocturnal seizures (6). The presence of night supervision seems protective; "supervision" could range from the presence of an individual in the same room to the deployment of devices such as listening devices (7). There is evidence suggesting that seizures could be identified using audio detection devices in at least $50 \%$ of individuals (8). A survey suggested that most parents found it useful to have some device, especially an audio monitor, to reduce stress and provide reassurance (9). There is no evidence to suggest that sophisticated monitoring systems are more sensitive to identify seizures than a simple audio device (10).

Cornwall a county in the UK (population 538,000 ) is implementing national guidance (3) of advising about SUDEP risk, focusing on modifiable risks (4). The county has a dedicated epilepsy service for people with ID. Since introducing a Checklist in 2011, all clinicians in the service use it at least annually to advice individuals, their families and support workers of risk of SUDEP and inform of changes from previous checks. This includes applying the Checklist, feeding back information (orally and in writing), storing the Checklist results on ehealth records and conducting regular updates. When people are supported by professional carers, advice is passed on to management, with a request to discuss the details of the person centred risk with all relevant care staff. Regular advice is given to all service attenders to use an audio monitor to screen for nocturnal events as this is potentially a modifiable risk.

We attempted to assess whether people with epilepsy and their families or support workers were SUDEP aware, could recall discussion about SUDEP risk and the role of nocturnal surveillance. We also attempted to determine if advice on night time surveillance was 
adopted and if this led to the identification of previously unknown nocturnal events. Lastly we attempted to identify differences between responses provided by carers in family settings as opposed to those in residential settings.

\section{Methods}

A simple, one page questionnaire was designed and approved by the department clinicians. It was then modified based on constructive feedback from families and carers (appendix 2). All adults with epilepsy and ID who were under active follow up during July 2017 in Cornwall were identified and their carers sent the questionnaire with a return envelope. Documented person centred counselling of SUDEP using the Checklist was documented for all service attendees. The data was stored on an Excel spread sheet using only an identifier number. The project was registered as service evaluation with the local NHS Trust.

Individuals were categorised into living in 'residential' or 'family' care. 'Family' was defined as being in the family home, shared or supported living where family or friends had regular input to care. Those who did not respond to the questionnaire were contacted once by telephone. The questionnaire, to ensure consistency was completed by support workers or family members. Replies stated as 'not sure' were considered as a 'no'.

Standard inferential statistics was performed. Differences in questionnaire responses between the residential and family groups were compared using Fisher's exact test. The level of statistical significance was set at alpha $=0.05$.

\section{Results}

There were 170 people under active follow up in July 2017, 55\% ( $n=94)$ with families and the remaining in residential settings. Of the 121 (71\%) returned questionnaires, 75\% ( $n=56)$ were from the residential group and $69 \%(n=65)$ from the family group.

Table 1 provides demographic details. Around two thirds indicated to have nocturnal seizures (69\%). People living with their family were more likely to have nocturnal seizures than those with in residential care $(p<0.05)$. No difference was noted in affirmative response between the residential and family population around presence of night time monitoring. Over $80 \%$ of both groups were aware of SUDEP. There was, however, a significant difference in the recollection between the two groups about the person centred SUDEP discussion with two third (65\%) of families recalling compared to two fifth (39\%) of professional carers ( $p$ $=0.006$ ). No statistical significance was seen between the two groups on their recollection of night time monitoring discussions. Of the total survey sample $(n=121), 35 \%(n=42)$ had no previous nocturnal monitoring system in place and did so post SUDEP advice. Of the 42, nocturnal seizures were found in 32. None of these 32 had previously been known to have nocturnal seizures. In $76 \%$ (95\% Cl: $63 \%$ to $89 \%$ ) the monitor helped identify previously unknown nocturnal seizures. 


\section{Discussion}

We assessed how structured risk advice given in a routine clinic is assimilated and used to mitigate SUDEP risk in a population with epilepsy and ID. Everyone in the target population had received the same advice, in a structured way through the SUDEP checklist. Our findings suggests that structured communication helps reduce risk.

The response rates of over two thirds are a major strength of the exercise. The main limitation is that the small size of the population affecting the precision of the estimates. Another potential source of bias is the discrepancy in the size of the two groups. The differences seen in the two groups may have been statistically significant if there were larger numbers. Other limitations include the use of self-reported measures and the potential for responder recall bias. Acknowledgement is made that the findings are associations and it is not clear to what extent the results can be generalised to other populations. While every attempt was made to liaise with the principal carer, this was not always possible particularly for those service users in residential settings, which may have impacted the quality of the feedback.

Another limitation is that the presumption that people who live in residential homes would have had all professional carers informed of SUDEP risk via the care manager. This, however, might not have happened in every case and may have contributed to the lower rate of person centred awareness in the residential facility group versus the family group.

People with ID and epilepsy placed in professional care settings are more likely not have person centred risk advice implemented, possibly due to the nature of the setup and a lack of information dissemination within the care team. Professional care usually involves multiple people, staff rotation and diverse environment.

No difference was noted in affirmative response between the residential and family population around presence of night time monitoring. It could be argued that this mean it's not necessary to counsel about SUDEP risk and nocturnal supervision. Our view is that SUDEP counselling is necessary for all people with epilepsy and their carers. The findings suggest in the family group interventions were put in place with clear knowledge and insight of the issue. The residential group appear to have done so from a 'duty of care' perspective due to clinical recommendations made but possibly without, having understanding of why such monitoring is needed. But for both groups the SUDEP counselling had been paramount in influencing this change.

While it was good see in practice the intervention advised being adhered, the lack of person centred knowledge of SUDEP in the residential population leaves concerns of a dearth of awareness of other factors which can influence SUDEP risk $(11,12)$. This makes people in residential care more likely to be failed than those with their families. 
We found that the implementation of nocturnal surveillance may identify previously unrecognised events so people with epilepsy and ID should be offered nocturnal monitoring. Choice may depend on the individual's cognitive ability to make informed decisions and a 'one size fits all' approach is unlikely to be helpful. Surveillance should be based on individual risk and need. There might be periods when surveillance can be withdrawn or alternately introduced based on changes in seizure and life style patterns. With regard to ID, while attempts must be made to consider and incorporate the wishes of the individual regarding invasion into their personal space by monitoring, many might struggle to exercise such a choice. In such a situation consideration needs to be given not only to the level of cognition, or individual choice, but also to the level of overall disability including degree of ID, communication deficits, severity of epilepsy and multi-morbidity.

This study suggests that structured communication using tools such as the 'Checklist' helps reduce risk. Further there needs to be consideration of identification and mitigation of nocturnal seizures given their association with up to $70 \%$ of SUDEP deaths not only in the ID population but the larger general population with epilepsy.

People with ID go may go through different settings over their lifetime. They can be accompanied by carers with varied motivation, interest and involvement. Risk communication needs to be regular and tailored to match consistent feedback due to the changing profiles of people and their settings. It is important that risk messages be repeated by clinicians, incorporated into care plans and, where possible, a key person identified to take ownership of the risk issues. A cost effective intervention could be developing an electronic learning module for professionals working with people with ID and epilepsy the aim of which would be to ameliorate the issues outlined in the professional/carer group. 


\section{References}

1. Shorvon S, Tomson T. Sudden unexpected death in epilepsy. Lancet. 2011;378:20282038.

2. Maguire MJ, Jackson CF, Marson AG, Nolan SJ. Treatments for the prevention of Sudden Unexpected Death in Epilepsy (SUDEP). Cochrane Database Syst Rev. 2016 Jul 19;7:CD011792. doi: 10.1002/14651858.CD011792.pub2. Review.

3. National Institute for Health and Care Excellence. The epilepsies: the diagnosis and management of the epilepsies in adults and children in primary and secondary care. London: NICE; 2012. CG137.

4. Shankar R, Newman C, McLean B, Anderson T, Hanna J. Can technology help reduce risk of harm in patients with epilepsy? The British Journal of General Practice. 2015;65(638):448-449. doi:10.3399/bjgp15X686413.

5. Shankar R, Newman C, Hanna J, et al. Keeping patients with epilepsy safe: a surmountable challenge? BMJ Quality Improvement Reports. 2015;4(1):u208167.w3252. doi:10.1136/bmjquality.u208167.w3252.

6. Van Andel J M, Tele-epilepsy: Developing a multi-modal device for non EEG, extramural, nocturnal seizure monitoring Epilepsia; Jun 2013; vol. 54 ; p. 26-27

7. Langan Y, Sander J.W, Nashef L. Case-control study of SUDEP Neurology; Apr 2005; vol. 64 (no. 7); p. 1131-1133

8. Arends J, Van Hoek D., Van Mierlo P, Van Dorp J, Kramer N, Van Der Vorst D et al. Diagnostic accuracy of audio based seizure detection in patients with severe epilepsy and a mental impairment E \& B, September 2016, Volume 62, Pages 180-185

9. Chinnappan S, Rajdev S, Singh R. Epilepsy alarm/monitor-Questionnaire survey of the Parent's perception of the use of the epilepsy alarm Archives of Disease in Childhood; Apr 2014; vol. 99(suppl A)

10. Jory C, Shankar R, Coker D, McLean B, Hanna J, Newman C. Safe and Sound? A systematic literature review of seizure detection methods for personal use. Seizure 2016;36:4-15

11. Shankar R, Donner E, McLean B, Nashef L, Tomson T Sudden Unexpected Death in Epilepsy -What Every Neurologist Should Know Epileptic Disorders Volume 19, Issue 1 March 2017 Pages 1-9

12. Shankar R, Henley WH, Boland C, Laugharne R, McLean B et al Decreasing the risk of SUDEP: Structured communication of risk factors for premature mortality in people with epilepsy. European Journal of Neurology (2018) https://doi.org/10.1111/ene.13651 
Table 1. Results of the questionnaire including demographics

\begin{tabular}{|c|c|c|c|c|}
\hline & $\begin{array}{l}\text { Grand total } \\
\qquad \mathrm{n}=\end{array}$ & $\begin{array}{l}\text { Residential } \\
\quad(R) n=\end{array}$ & $\begin{array}{l}\text { Non- } \\
\text { residential } \\
\text { (NR) } n=\end{array}$ & $\begin{array}{c}\text { Comparing } \mathbf{R} \\
\text { versus NR } \\
\mathrm{p} \text { - value for test } \\
\text { of difference* }\end{array}$ \\
\hline Total caseload & 170 & $76(45 \%)$ & $94(55 \%)$ & \\
\hline Postal replies & 121 & $56(74 \%)$ & $65(69 \%)$ & \\
\hline Question & \multicolumn{3}{|c|}{ Affirmative responses } & \\
\hline $\begin{array}{l}\text { Do they have generalised } \\
\text { seizures? }\end{array}$ & $97 / 121(80)$ & $\begin{array}{l}46 / 56 \\
(82 \%)\end{array}$ & $\begin{array}{l}51 / 65 \\
(78 \%)\end{array}$ & 0.66 \\
\hline $\begin{array}{l}\text { Do they have nocturnal } \\
\text { seizures? }\end{array}$ & $\begin{array}{r}83 / 121 \\
(69 \%) \\
\end{array}$ & $\begin{array}{l}33 / 56 \\
(59 \%) \\
\end{array}$ & $\begin{array}{l}50 / 65 \\
(77 \%) \\
\end{array}$ & 0.049 \\
\hline $\begin{array}{l}\text { Do they have night } \\
\text { monitoring? }\end{array}$ & $104(86 \%)$ & $\begin{array}{l}51 / 56 \\
(91 \%)\end{array}$ & $\begin{array}{l}53 / 65 \\
(82 \%)\end{array}$ & 0.19 \\
\hline Audio & $60(58 \%)$ & $29(57 \%)$ & $31(58 \%)$ & \\
\hline $\mathrm{AV}$ & $12(11.5 \%)$ & $4(7.8 \%)$ & $8(15 \%)$ & \\
\hline Intermittent checks & $55(53 \%)$ & $31(61 \%)$ & $24(45 \%)$ & \\
\hline Alarm & $6(5.7 \%)$ & $4(7.8 \%)$ & $2(3.7 \%)$ & \\
\hline Saturation monitor & $2(1.9 \%)$ & 0 & $2(3.7 \%)$ & \\
\hline Same room & $6(5.7 \%)$ & 0 & $6(11 \%)$ & \\
\hline (More than 1 method) & $32(31 \%)$ & $12(23.5 \%)$ & $20(37 \%)$ & \\
\hline Are you aware of SUDEP? & $98(81 \%)$ & $\begin{array}{l}45 / 56 \\
(80 \%) \\
\end{array}$ & $\begin{array}{l}53 / 65 \\
(82 \%) \\
\end{array}$ & $>0.999$ \\
\hline $\begin{array}{l}\text { Can you remember a person } \\
\text { centred discussion about } \\
\text { SUDEP? }\end{array}$ & $64(53 \%)$ & $\begin{array}{l}22 / 56 \\
(39 \%)\end{array}$ & $\begin{array}{l}42 / 65 \\
(65 \%)\end{array}$ & 0.006 \\
\hline $\begin{array}{l}\text { Can you remember a } \\
\text { discussion around Nocturnal } \\
\text { Monitoring? }\end{array}$ & $74(61 \%)$ & $\begin{array}{l}33 / 56 \\
(59 \%) \\
\end{array}$ & $\begin{array}{l}41 / 65 \\
(63 \%) \\
\end{array}$ & 0.71 \\
\hline $\begin{array}{l}\text { Did the discussion change } \\
\text { practice for Nocturnal } \\
\text { Monitoring? }\end{array}$ & $\begin{array}{l}42 / 74 \\
(57 \%)\end{array}$ & $17 / 33(52 \%)$ & 25/41(61\%) & 0.48 \\
\hline $\begin{array}{l}\text { Did the use of Nocturnal } \\
\text { Monitoring following advice } \\
\text { given, identify previously } \\
\text { unknown nocturnal seizures? }\end{array}$ & $\begin{array}{l}32 / 42 \\
(76 \%)\end{array}$ & $14 / 17(82 \%)$ & $\begin{array}{l}18 / 25 \\
(72 \%)\end{array}$ & 0.49 \\
\hline
\end{tabular}




\section{Appendix 1 - The SUDEP and Seizure Safety Checklist ("Checklist")}

The Checklist is a free, national award-winning (British Medical Journal 2016) risk communication tool for clinicians which encompasses known modifiable and non-modifiable risk factors of SUDEP and associated concerns with a view to:

assist clinicians to open a positive discussion with people about epilepsy and risk assessment;

support a person-centred discussion of risk, focusing on whether known risk factors apply to a particular patient;

help clinicians educate people with epilepsy about their personal risk and possible lifestyle changes which might reduce those risks;

promote the safety goal by identifying modifiable risk factors which may guide management;

create documentary evidence for clinicians on the impact of the treatment plan over time, and demonstrates effective clinical governance while enhancing individual safety;

Provide some assurance to bereaved families that every effort was made to reduce risk and prevent a fatality when a death occurs.

An example on how to administer is provided (https://www.youtube.com/watch?v=Z9KHQvsapAc ); clinicians can also register for the tool, or find out more via www.sudep.org/checklist . The Checklist is managed by SUDEP Action (Secretariat and PPI Leads) and Cornwall Partnership NHS Foundation Trust (Clinical Leads). 


\section{Appendix 2 - Survey questionnaire}

Patient name

Form number

Dear patient/carer,

Re: effectiveness of safety advice given by our service

Our epilepsy team is conducting a service evaluation of how impactful our advice strategy of monitoring safety due to seizures especially when the person with epilepsy is alone as at night. As patient/carer of our service we would be grateful if you could take a few minutes to answer the questions below to the best of your knowledge to help improve our service to you. In most questions the best answer you feel suitable just needs to be circled. Please feel free to provide any comments in the spaces between questions.

Does the person you care for have seizures?

Are they generalised seizures?

Do seizures happen or have happened at night?

Do you monitor the person at night?

If so which of these apply (please tick all eligible) -

\begin{tabular}{|l|l|}
\hline Audio baby monitor & \\
\hline Audio - Video baby monitor & \\
\hline Physical checks - 15 minutes/ 30 minutes/hourly/other & \\
\hline Commercial epilepsy alarms (like bed mats etc.) & \\
\hline Oxygen Saturation equipment & \\
\hline Sleep in the same room & \\
\hline other & \\
\hline
\end{tabular}

Do you check if a device is used works satisfactorily? -if yes how regularly - daily/ every week/monthly/ other

Are you aware of Sudden Unexpected Death in Epilepsy (SUDEP)? Yes/No/Not sure Have you had a discussion of SUDEP in relation to the person in your care? Yes/No /not sure 
Have you received advice for nocturnal audio monitoring? Yes/No/Not sure If advice received by whom - Epilepsy specialist/ clinician/GP/media/ self-researched When was it received? 0-5 years/ 5-10 years/ other/never received Did the advice change your existing monitoring practice? Yes/no/Not sure Did monitoring pick up previously unidentified events and concerns? Yes/No/Not sure 